\title{
A EQUIVOCIDADE NA CIRCULAÇÃO DO CONHECIMENTO CIENTÍFICO
}

\author{
Suzy Lagazzi
}

Resumo: Na relação entre a produção do conhecimento considerado como científico e sua divulgação, proponho-me a discutir a equivocidade, compreendida por Michel Pêcheux como a sobreposição de sentidos a partir de diferentes posições do sujeito. Tomo como objeto para minha análise capas da Revista Pesquisa FAPESP, uma revista de divulgação científica publicada pela Fundação de Amparo à Pesquisa do Estado de São Paulo. Tendo como referencial teórico a Análise do Discurso materialista, que trabalha na relação entre a linguistica, o materialismo bistórico e a psicanálise, exploro a composição do verbal e da imagem na busca por compreender o atravessamento da ciência pela informação.

Palavras-chave: Divulgação científica. Análise do Discurso. Análise palavra/imagem.

\section{INTRODUÇÃO: FORMULANDO A QUESTÃO}

No amplo terreno da divulgação do conhecimento, me disponho a uma análise que foca o equívoco na relação entre a produção que se legitima como científica e sua divulgação (cf. ORLANDI, 2001). Equívoca relação porque, no processo da divulgação do conhecimento científico, estão concernidos, por um lado, o próprio conhecimento nomeado como científico, que se justifica em si mesmo como necessidade indiscutível para o desenvolvimento da sociedade moderna e que, portanto, precisa e deve circular; e por outro lado os espaços de divulgação que se apresentam com interesses e determinações específicos, muitas vezes presididos pelo pré-construído ${ }^{1}$ da informação utilitária, que não se conjuga com a indiscutível evidência da necessidade científica e faz perguntar: como este conhecimento se adequará ao público leitor? É sobre essa adequação, que Orlandi (2001a) chama de transferência da ordem do discurso científico para a ordem do discurso jornalístico, que quero me debruçar enfocando o equívoco. Por um lado,

\footnotetext{
* Professora Doutora em Linguística do Instituto de Estudos da Linguagem - UNICAMP, SP. Email: slagazzi@gmail.com.

${ }^{1} \mathrm{O}$ conceito de 'pré-construído' pode ser entendido, na Análise do Discurso materialista, como um dizer anterior, que sustenta a possibilidade de novos dizeres. Cf. Pêcheux (1988). O pré-construído da informação utilitária pode ser resumido na terrível pergunta que nos assombra com o imediatismo de sua aplicação: para que isto serve?
} 
a especificidade de se produzir conhecimentos e compreensões no espaço da linguagem científica; por outro, o exercício de transformar esses conhecimentos e compreensões em objeto de consumo de um público leitor não especialista. Um percurso que do cientista ao público leitor deixa brechas e traz para a cena da divulgação do conhecimento diferentes efeitos de sentido que se sobrepõem a partir de diferentes posições do sujeito. Aí está a equivocidade da qual nos fala Michel Pêcheux (1990a).

\section{SITUANDO A LEITURA MATERIALISTA}

Efeito de sentido, posição-sujeito, equívoco. Conceitos-chave na Análise do Discurso materialista.

Entre muitos diferentes modos de nos referirmos à Análise do Discurso, gosto particularmente de retomar a afirmação de que ela é um dispositivo de leitura. E para fazer o gancho com os conceitos 'efeito de sentido' e 'posição-sujeito' acima referidos, sugiro que estendamos essa afirmação: a Análise do Discurso materialista é um dispositivo de leitura que busca compreender a interpretação em suas diferentes condições possíveis, na relação com os diferentes efeitos de sentido produzidos, para determinar as posições-sujeito que sustentam os gestos de interpretação ${ }^{2}$.

Temos aqui já vários pontos sobre os quais vale a pena nos determos com certo vagar.

Falar da leitura como um dispositivo não é uma maneira muito comum de entrar nesse campo. Mas justamente o termo 'dispositivo' quer chamar a atenção para o fato de que ler requer um trabalho pautado em princípios e procedimentos (Cf. ORLANDI, 1999). Na Análise do Discurso, compreendemos a leitura de uma maneira muito diferente daquela pela qual ela é normalmente entendida na escola, quando a preocupação é determinar o que o autor quis dizer, determinar o conteúdo do texto. A Análise de Discurso se posiciona questionando e criticando análises de conteúdo. Isso não significa que o conteúdo seja ignorado, mas sempre diremos que um texto pode receber diferentes

\footnotetext{
${ }^{2}$ Sobre a noção de "gestos de interpretação" cf. Orlandi (1996).
} 
interpretações. Da mesma forma que um texto se oferece a diferentes interpretações na relação com diferentes leitores, também um mesmo leitor poderá se significar em diferentes interpretações frente a um mesmo texto, quando em diferentes condições de produção. Para a perspectiva discursiva materialista, os sentidos são efeitos que se produzem sob determinações históricas, por isso não podemos deixar de perguntar quais as condições para que algo seja dito de uma determinada maneira para determinado(s) interlocutor(es) em determinado contexto sócio-histórico. E muito importante: sempre perguntaremos o que não está sendo dito e o que não pode ser dito naquelas mesmas condições. $\mathrm{O}$ que está sendo reafirmado e o que está sendo silenciado (Cf. ORLANDI, 1992)? Podemos pensar em outras condições de produção? Enfim, sempre perguntas que incidam sobre o processo de leitura. leitura?

E o que significa falar de diferentes condições possíveis para a

São várias as questões aqui implicadas. Ressaltei que um texto pode ter diferentes interpretações, mas ele não pode ter qualquer interpretação. Isto porque a materialidade do texto impõe limites para a produção dos sentidos. Importam as palavras usadas assim como a sintaxe do texto, no caso da materialidade verbal. Importam as imagens em seus vários elementos constitutivos, tais como as cores, a relação luz e sombra, a perspectiva, os traços no caso da materialidade visual. E no caso de um texto alocado no espaço digital, importam também os links, muitas vezes o movimento de imagens, a sonoridade e a musicalidade, em caso de vídeos. Enfim, são muitas as materialidades significantes ${ }^{3}$ sobre as quais os leitores se debruçam em seus percursos de interpretação.

Ao chamar a atenção para o trabalho simbólico com o significante, quero trazer um pouco do percurso trilhado por este conceito.

A abordagem conteudística da leitura, à qual já me referi um pouco acima, produz muita insatisfação quanto ao modo de se conceber o autor, a escrita e o texto, principalmente nas décadas de 60 e 70 do

\footnotetext{
${ }^{3}$ Cf. Lagazzi (2011). Ressalto que minha proposta da formulação 'materialidade significante' tem como preocupação, ao mesmo tempo, o investimento na perspectiva materialista e o trabalho simbólico com o significante.
}

LAGAZZI - A equivocidade... 
século passado. Para fazer frente a essa insatisfação, "o texto é tomado, por alguns estudiosos, como um espaço de possibilidades relacionais, a escrita como um processo envolvendo a sociedade e o autor não mais como uma figura constituída por inspiração" (Cf. LAGAZZIRODRIGUES, 2006). É quando começa a ter espaço na relação com o texto o trabalho com o significante verbal.

Retomando o conceito 'signo' a partir do livro Curso de Linguística Geral, escrito por dois alunos de Saussure a partir de anotações de suas aulas e publicado pela primeira vez em 1916, após sua morte, lemos:

Propomo-nos a conservar o termo signo para designar o total, e a substituir conceito e imagem acústica respectivamente por significado e significante; estes dois termos têm a vantagem de assinalar a oposição que os separa, quer entre si, quer do total de que fazem parte. (1979, p.81, grifos do autor)

Nesta definição proposta no Curso de Linguística Geral, 'significado' e 'significante' vêm colados um ao outro tal como as páginas verso e anverso de uma folha de papel. A compreensão trazida pelo Curso é de que entre esses dois conceitos se estabelece uma relação biunívoca, com a indissociabilidade entre significado e significante. A unidade de referência, portanto, é o signo, e tanto significado quanto significante ficam localizados internamente ao signo. Juntos, os conceitos 'sistema' e 'signo' permitiram que a língua, definida como um sistema de valores formado por signos, fosse estudada como um conjunto fechado, no qual haveria total estabilidade entre os vários elementos - os signos - internos a esse sistema. A partir dessas concepções desenvolveram-se os estudos formais, que estabeleceram como unidade mínima de análise o fonema e como unidade máxima a frase. Fonética e fonologia, morfologia e sintaxe são as disciplinas que congregam os estudos formais, buscando estabelecer os sistemas fonológicos, morfológicos e sintáticos das línguas. Nesse espaço dos estudos formais, portanto, não resta qualquer possibilidade para que significado e significante se constituam numa relação de movimento entre si.

Os estudos formais reinaram fortemente na linguística por meio século, até que na década de 60 do século XX o texto é tomado como 
unidade possível de análise linguística. Como apontado acima, o texto passa a ser olhado, por alguns autores, como um espaço de possibilidades relacionais. É interessante observar que esse movimento em relação ao texto se faz como resposta tanto ao formalismo linguístico quanto ao conteudismo literário e comunicacional.

Nesse espaço de possibilidades relacionais, então, começa-se a perguntar, por exemplo, pelo modo de estruturação do texto, pela distribuição das palavras no texto, questões que permitem que o olhar não se foque no conteúdo. Além dessas questões ligadas à estrutura, também o sentido passa a ser alvo de um trabalho de desnaturalização da literalidade, de crítica à dicotomia denotação/conotação. $\mathrm{E}$ nesse novo modo de se conceber a leitura do texto, abre-se espaço para o trabalho com o significante verbal.

Como nos mostram Gadet e Pêcheux (2004), para a discussão do estatuto do significante na língua é fundamental o retorno a Saussure, em algumas questões extremamente consequentes. Embora a leitura que se legitimou do Curso tenha sido aquela que fixa a língua como um sistema de valores, na dicotomia língua/fala, a complexidade da reflexão de Saussure sobre a linguagem fica visível se compararmos o Curso a seu trabalho sobre os anagramas. Também só conhecida após sua morte, a reflexão sobre os anagramas apresenta o estudo da repetição dos sons na poesia latina, na forma de anagramas de nomes próprios, que são palavras ou versos formados pela transposição dos sons (ou das letras correspondentes) de um nome próprio (por exemplo, em América podemos ler Iracema). É importante considerar que os anagramas se caracterizam pela repetição das formas sonoras, enfatizando a relação significante na língua. Essa relação significante diz respeito, nas palavras de Gadet e Pêcheux (2004) à poesia da língua:

Diante das teorias que isolam o poético do conjunto da linguagem, como lugar de efeitos especiais, o trabalho de Saussure (tal como ele é, por exemplo, comentado por Starobinski) faz do poético um deslizamento inerente a toda linguagem: o que Saussure estabeleceu não é uma propriedade do verso saturnino, nem mesmo da poesia, mas uma propriedade da própria língua. O poeta seria apenas aquele que consegue levar essa propriedade da linguagem a seus últimos limites [...] (2004, p. 58) 
Também sobre a reflexão apresentada no Curso Gadet e Pêcheux voltam com especial consequência. Os autores chamam a atenção sobre a noção de valor, que nos diz que um signo vale por aquilo que os outros não são. Mais exatamente, podemos ler no Curso:

Quando se diz que os valores correspondem a conceitos, subentende-se que são puramente diferenciais, definidos não positivamente por seu conteúdo, mas negativamente por suas relações com os outros termos do sistema. Sua característica mais exata é ser o que os outros não são. (1979, p.136)

Essa definição de valor pela negatividade é de uma agudeza e consequência ímpar! Valer por "aquilo que os outros não são" nos obriga, necessariamente, a desfocar do interior de um elemento para olhar para o conjunto dos elementos em suas diferenças. Uma característica só importa na diferença com outras! É uma maneira eficientíssima de nos obrigarmos a nos despregar do conteúdo e colocar em movimento o caráter relacional em um conjunto aberto. Este é outro ponto muito importante: a noção de sistema fica recusada, justamente pelo fechamento que imobiliza qualquer possibilidade de deslocamento.

Volto ao ponto 'colocar em movimento o caráter relacional em um conjunto aberto'. $\mathrm{Na}$ perspectiva discursiva materialista, os procedimentos analíticos sempre enfatizam o que nomeamos como 'relação a', ou seja, sempre remetemos um elemento a outros, buscando no exercício parafrástico contrapontos que nos permitam compreender a produção dos sentidos na evidência que resulta do trabalho da ideologia.

Também no que diz respeito às relações associativas, Gadet e Pêcheux (2004) tecem considerações importantes a partir do Curso de Linguistica Geral. Os autores lembram que Saussure reconhece quatro eixos de associações possíveis na língua: associação com base no radical (ensinamento/ensinar), associação entre significados (ensinamento/aprendizagem), associação com base nos afixos (ensinamento/desfiguramento), e associação pelo significante (ensinamento/elemento). Este quarto eixo, ressaltam, o da associação pelo significante, dá abertura para que os deslocamentos associativos abriguem o imprevisto na língua, mostrando que a língua escapa ao 
sujeito. Somos sujeitos de linguagem, pegos na poesia da língua. Se, por um lado, não há pensamentos e ideias anteriores à linguagem, anteriores à relação entre significantes e significados, também não há língua independente dos sujeitos que a fazem circular e, na incompletude que a constitui, fazem-na se deslocar nos trajetos que a história permite.

Neste percurso de reflexão que institui o foco no significante verbal, há uma mudança importante de estatuto: o significante não é mais tomado como a contraparte do significado e passamos a ter a primazia do significante, consolidada pelos trabalhos de Jacques Lacan na psicanálise. Nas palavras de Ducrot e Todorov (1982, p. 414), "uma viragem que marca a história do conceito de signo", que antes sempre se pautara pelo domínio do significado. Uma viragem que marca também o domínio do texto, da interpretação e do sujeito. O texto pode ser pensado como um espaço de possibilidades relacionais e não mais como um conjunto de ideias do autor, a interpretação não mais uma questão de conteúdo, e o sujeito não mais senhor dos sentidos.

$\mathrm{Na}$ perspectiva discursiva materialista, endossamos essa concepção de que o sujeito não domina os sentidos, não diz o que quer dizer, mas sim o que é possível ser dito, a partir das posições-sujeito que o constituem. Somos pegos em possibilidades que a língua nos oferece em sua relação com a história, pegos em evidências que nos identificam nas posições-sujeito que recortam os dizeres a partir das condições de produção. A perspectiva discursiva materialista reconhece que as condições de produção funcionam como determinações históricas que não ficam visíveis para o sujeito conscientemente, mas que o coagem a responder às demandas que se impõem a partir das relações de força que organizam nossa sociedade capitalista, uma sociedade que se estrutura pela venda da força de trabalho de todos, nas mais diferentes funções que possamos ocupar e com os mais diferentes salários que recebamos. Do serviço braçal ao mundo dos negócios, passando pela intelectualidade, todos nos vendemos, obrigatória e livremente, com a enorme diferença de alguns subsistirem e outros escolherem as melhores aplicações financeiras. Mas essa enorme diferença não atingirá o modo de produção capitalista enquanto quisermos, todos, um melhor salário! Sendo sujeitos-de-direito, responsabilizados por nossos gestos e dizeres, livres e iguais segundo os preceitos capitalistas jurídicos, nosso modo de existência possível nesta organização social capitalista está no gesto de 
"livremente" entrarmos em circulação no "mundo do trabalho", "por nossa livre vontade trocarmos nossas capacidades e habilidades pelo melhor salário possível!" (Cf. NAVES, 2000).

Voltamos ao equívoco. Tomemos o mundo do trabalho, no qual temos o enunciado "Seu salário faz jus ao seu esforço". Se proferido por um empregador que avalia bem o empregado em questão, 'esforço' será parafraseado por 'grande esforço/ eficiência', o que indicará um salário considerado bom. Se, contrariamente, este enunciado for proferido por um empregador que avalia mal esse empregado, 'esforço' será parafraseado por 'pouco esforço/ preguiça', o que indicará um salário considerado baixo. Aliás, observemos a equivocidade da expressão "bom salário". Bom para quem?

A equivocidade, tal qual discutida por Pêcheux (1990a), é constitutiva da linguagem. $O$ autor nos mostra a importância de perguntarmos pelos sentidos em suas condições de produção, de colocarmos as interpretações em suspenso. Em sua análise do enunciado "Ganhamos", nos mostra a consequência da expansão da pergunta e a grande diferença quando se trata do campo esportivo ou do campo político. No campo político as consequências dizem respeito às relações sociais, muito diferentes das relações entre times.

Pensar os sentidos como efeitos produzidos sobre a cadeia significante em condições de produção é dar consequência ao primado do significante, e não apenas do significante verbal. É na relação entre a materialidade significante e a história que os sentidos se produzem. Nossa análise tenta dar consequência a isso!

\section{DELIMITANDO O CORPUS}

Essas considerações se fazem presentes a partir da análise a que me proponho e que toma como seu objeto as capas da Revista Pesquisa FAPESP, uma publicação relevante para a discussão do equívoco na relação entre a produção e a divulgação do conhecimento científico. Inicialmente uma revista endereçada apenas ao público acadêmico, hoje a Revista Pesquisa FAPESP se oferece ao público leitor não especialista argumentando sobre sua qualidade: 
Manter-se informado é fácil. Informar-se com qualidade são outros quilates.

Leia a PESQUISA FAPESP e fique por dentro do que os cientistas andam estudando, investigando, pesquisando. Muitos livros didáticos reproduzem textos da PESQUISA FAPESP. Assinando, ou comprando a revista nas bancas, você poderá ler esses textos em primeira mão. Confira: Em 2010, todas as questões de química do vestibular da Unicamp tiveram como base informações publicadas na PESQUISA FAPESP. Exames de avaliação de estudantes do ensino médio também recorreram a conhecimentos veiculados pela revista.

PESQUISA FAPESP é referência de qualidade nas áreas diversas da ciência $\mathrm{e}$ das humanidades. Se você é estudante, a revista é uma ferramenta para novos conhecimentos e para a fixação da aprendizagem.

Se você é professor, a revista é uma ferramenta para aprofundar seus conhecimentos e oferecer temas e ideias para suas aulas.

Se você não é estudante nem professor mas ama a informação de qualidade, a PESQUISA FAPESP tem tudo a ver com você. (http://revistapesquisa.fapesp.br/)

A FAPESP - Fundação de Amparo à Pesquisa do Estado de São Paulo se legitima como uma instituição de grande exigência no que diz respeito à qualidade dos projetos por ela financiados. Portanto, faz todo sentido o foco nessa imagem da qualidade, marcado nas formulações "informar-se com qualidade, referência de qualidade, informação de qualidade" presentes no "texto marketing" para novas assinaturas, acima copiado. Uma revista dirigida àqueles que querem "ficar por dentro do que os cientistas andam estudando, investigando, pesquisando", querem "conferir que PESQUISA FAPESP é referência de qualidade nas áreas diversas da ciência e das humanidades", "amam a informação de qualidade": pessoas qualificadas. Mas é importante que essas pessoas qualificadas se interessem pelas matérias publicadas e legitimem a revista em sua circulação. Daí o desafio em tornar consumível "o que os cientistas andam estudando, investigando, pesquisando nas áreas diversas 
da ciência e das humanidades". Uma aposta da revista: a aliança com a afirmação da informação de qualidade! No entanto, algumas incisas são esclarecedoras: a Pesquisa FAPESP traz informação sobre pesquisa de qualidade, traz informação sobre produção científica de qualidade. Temos um movimento de atravessamento da ciência pela informação, e é sobre esse atravessamento que quero fazer incidir minha análise.

Sendo o lugar de entrada do leitor, a capa de uma revista é espaço de imbricação entre imagens e enunciados verbais e na imbricação dessas diferentes materialidades significantes (Cf. LAGAZZI, 2011) que compõem as capas de revistas se aguça, a meu ver, os funcionamentos discursivos significativos de cada revista. No caso de Pesquisa FAPESP, temos em suas capas um espaço de textualização (Cf. ORLANDI, 2001 b) privilegiado para a compreensão, nessa revista, do funcionamento da equivocidade na relação entre a produção do conhecimento científico e sua divulgação.
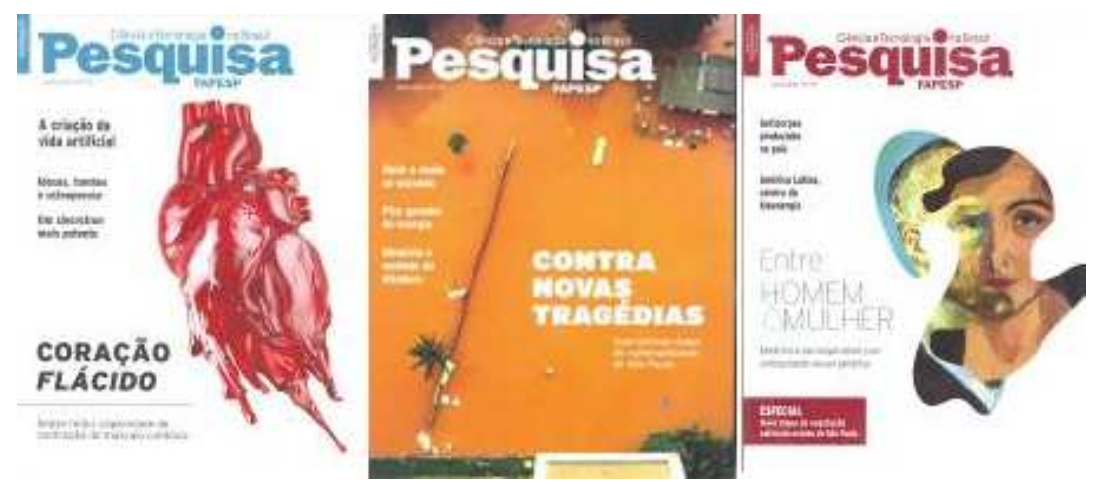

Figura 1 - Capas dos exemplares de Junho a Abril

Fonte: Revista Ciência e Tecnologia no Brasil: Pesquisa FAPESP 


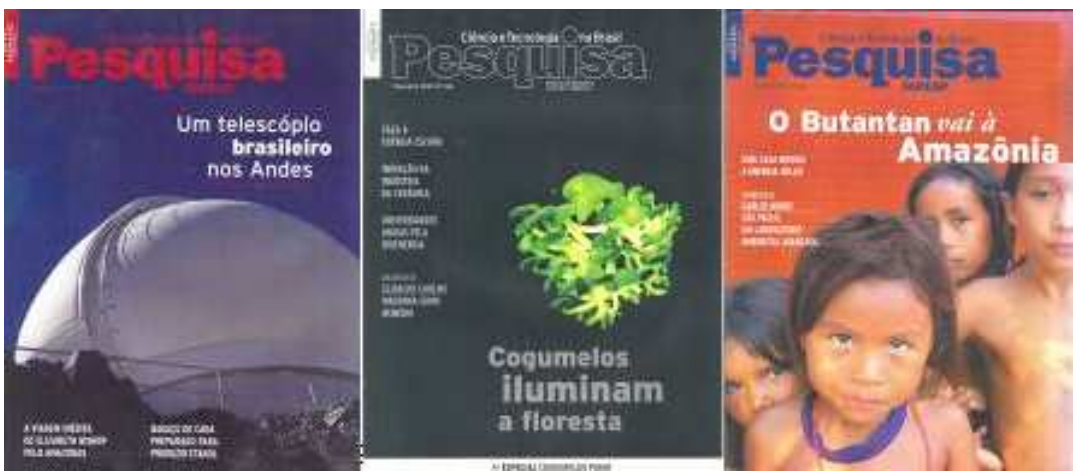

Figura 2 - Capas dos exemplares de Março a Janeiro

Fonte: Revista Ciência e Tecnologia no Brasil: Pesquisa FAPESP

As seis capas selecionadas para análise correspondem ao período de janeiro a junho de 2010. Podemos observar que a estruturação da capa de Pesquisa FAPESP sempre apresenta um enunciado principal, grafado em letras destacadas, e que está em relação com a imagem na capa. Foco minha análise na remissão entre o enunciado em destaque e a imagem, perguntando como se significa nessa remissão a ciência atravessada pela informação.

\section{A ANÁLISE}

Pensando em termos do efeito regular que perpassa todas as capas, é importante observar que elas ao mesmo tempo enunciam e visibilizam novos fatos: o Butantan vai à Amazônia, cogumelos iluminam a floresta, há um telescópio brasileiro nos Andes, medicina e psicologia lidam com ambiguidade sexual genética, Inpe entrega mapa da vulnerabilidade de São Paulo, sepse reduz capacidade de contração do músculo cardíaco. $\mathrm{Na}$ enunciação desses novos fatos, as capas apresentam enunciados em destaque com uma estrutura elíptica, que produzem como efeito o 'anúncio' de uma novidade: $\boldsymbol{O}$ Butantan vai à Amazônia, Cogumelos iluminam a floresta, Um telescópio brasileiro nos Andes, Entre HOMEM \& MULHER, 
CONTRA NOVAS TRAGÉDLAS, CORAÇÃO FLÁCIDO. As imagens, diremos, 'espacializam' sentidos desses enunciados.

\section{O Butantan vai à Amazônia (Janeiro 2010 - N¹67)}

O Butantan, um renomadíssimo centro de pesquisa na área biomédica, responsável pela quase totalidade dos soros e vacinas produzidos no Brasil, vai à Amazônia, região que em sua grande parte fica localizada em território brasileiro e que abriga interesses expressivos para um centro de pesquisa como o Butantan. Mesmo com o acréscimo dessas duas incisas, fica a pergunta de qual a razão pela qual se dá esse gesto do Instituto Butantan em direção à Amazônia. A falta da razão reforça o próprio gesto. Em sua estrutura elíptica, o enunciado anuncia uma nova relação entre o Butantan e a Amazônia, produzindo expectativa quanto a isso que se afirma como uma novidade. O enunciado cumpre o seu papel de levar o leitor ao artigo para que a relação entre o Butantan e a Amazônia fique esclarecida. Compondo com esse enunciado, a imagem da capa espacializa a Amazônia nos rostos das crianças indígenas.

Cogumelos iluminam a floresta (Fevereiro 2010 - No168)

$\mathrm{O}$ enunciado, em sua estrutura elíptica, não apresenta qualquer indício de como cogumelos podem vir a iluminar uma floresta, o que reforça o fato em sua surpreendente novidade. Fungos que em várias de suas espécies são considerados iguarias, os cogumelos são conhecidos pela grande maioria das pessoas em sua cor clara e opaca, sem qualquer luminosidade. $O$ efeito de se anunciar a iluminação da floresta por cogumelos incita o leitor a buscar o esclarecimento dessa novidade. $\mathrm{Na}$ composição com o enunciado, a imagem dos cogumelos fluorescentes contrastando com o fundo negro da capa espacializa essa afirmada capacidade de iluminação. Resta saber como isso é possível.

Um telescópio brasileiro nos Andes (Marco 2010 - N¹69)

O enunciado anuncia elipticamente a existência de um telescópio brasileiro nos Andes, afirmando um desencontro entre o espaço territorial chileno e a tecnologia brasileira. Por que um telescópio brasileiro não se encontra em território brasileiro? Nesse desencontro 
elíptico de nacionalidades se constrói um fato novo para a colaboração científica. O Brasil levar seu conhecimento astronômico a um outro país o coloca em posição de autonomia em pesquisa, deslocando a imagem de colonização científica que ainda é bastante forte quando pensamos a relação científica entre o Brasil, os Estados Unidos e vários países europeus, por exemplo, todos imaginariamente estabilizados como países do primeiro mundo e como mais desenvolvidos cientificamente. Nesse fato novo de colaboração científica em que o Brasil se afirma como protagonista, a imagem em evidência do telescópio espacializa sua presença em uma composição que torna incontestável a primazia da tecnologia brasileira no exterior. Cabe ao leitor buscar compreender essa nova posição em que o Brasil se significa.

Entre HOMEM \& MULHER - Medicina e psicologia lidam com ambiguidade sexual genética (Abril 2010 - N¹70)

A estrutura elíptica do enunciado 'Entre HOMEM \& MULHER' dispersa sua interpretação, que o leitor só consegue especificar quando ancora o enunciado na expressão 'ambiguidade genética', presente na formulação que segue o enunciado e o complementa, anunciando o fato de a medicina e a psicologia lidarem com uma questão nomeada como 'ambiguidade sexual genética'. Entre ser HOMEM e/ou ser MULHER há uma ambiguidade genética, afirma a capa da revista de abril. Dupla novidade: por um lado, no fato do investimento feito pela medicina e pela psicologia; por outro lado, no conjunto da formulação 'ambiguidade sexual genética', que o leitor terá que desvendar lendo a matéria. A dispersão que o enunciado sustenta entre ser homem e/ou mulher fica espacializada no entrelaçamento que a imagem exibe da afirmada ambiguidade sexual genética. $\mathrm{Na}$ dispersão, uma composição que se entrelaça.

CONTRA NOVAS TRAGÉDIAS - Inpe entrega mapa da vulnerabilidade de São Paulo (Maio 2010 - N¹71)

A leitura do enunciado CONTRA NOVAS TRAGÉDIAS em sua estrutura elíptica faz com que o leitor lance seu olhar em busca de uma formulação que lhe responda o que foi feito ou está sendo feito contra novas tragédias. E o que o olhar do leitor encontra num primeiro 
momento é a imagem da tragédia materializada em uma enchente, com as águas lamacentas em seu tom laranja ocupando todo o fundo da capa. Uma composição que impacta. Logo abaixo do enunciado CONTRA NOVAS TRAGÉDIAS, encontramos outro enunciado que anuncia que o Inpe entrega mapa da vulnerabilidade de São Paulo. O efeito é o de que esse é um fato novo "contra novas tragédias". Mas o leitor deverá sair em busca de ler como o conhecimento da vulnerabilidade pode ser transformado em gestos efetivos, já que a imagem espacializa em tragédia essa vulnerabilidade.

CORAÇÃO FLÁCIDO - Sepse reduz capacidade de contração do músculo cardíaco (Junho $2010-N^{\circ} 172$ )

Nesta capa de junho o enunciado elíptico CORAÇÃO FLÁCIDO formula uma relação em aberto entre coração e flacidez, que só fica contextualizada pelo enunciado que anuncia o fato novo de que sepse reduz. a capacidade de contração do músculo cardíaco. Ora, mas o que vem a ser 'sepse'? O fato novo fica em parte não compreendido, postulando a necessidade de que o leitor busque na matéria a resposta para sua pergunta. $\mathrm{Na}$ imagem que compõe com o enunciado verbal, a espacialização da flacidez em uma visibilidade bastante estilizada.

\section{ALGO A DIZER}

Nas capas analisadas, observamos que a imbricação entre imagem e enunciado produz o efeito de veracidade sobre os fatos enunciados como novos pelo efeito verbal de 'anunciação' e pelo efeito visual de 'espacialização'. No que diz respeito ao sentido de ciência atravessado pelo de informação, vemos que na revista Pesquisa FAPESP a cientificidade fica significada na veracidade de novos fatos.

No entanto, nesse processo discursivo em análise, observo que na relação entre o enunciado verbal e a imagem há momentos em que a falha irrompe na produção da veracidade. Volto à capa que espacializa a Amazônia nos rostos das crianças indígenas. 


\section{Figura 3 - Capa Janeiro}

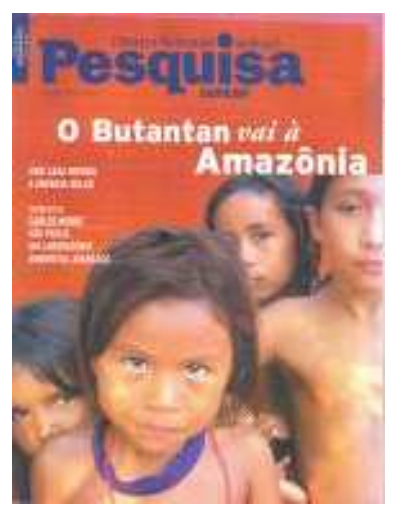

Fonte: Revista Ciência e Tecnologia no Brasil: Pesquisa FAPESP

É preciso perguntar: O Butantan vai a que Amazônia? Como devemos compreender a extensão significante entre 'Amazônia' e esses rostos de crianças indígenas estampados na capa da Pesquisa FAPESP de janeiro de 2010? Como não estranhar uma espacialização que se abre em tantas brechas? Estes rostos nos encaram e nos falam de muito mais que a Amazônia. Ao mesmo tempo, a Amazônia é muito mais que a terra de indígenas. O enunciado 'Amazônia' e estes rostos nos significam numa memória discursiva que traz a história em muitos percursos e o social em sua diferença constitutiva. Nesse movimento de espacialização de sentidos, a imagem e o enunciado se escapam. Esta capa de janeiro de 2010 de Pesquisa FAPESP enuncia muito mais que o fato novo de que o Butantan vai à Amazônia. Nossa escuta se abre na relação entre o enunciado 'Amazônia' e os rostos que nos encaram com olhares certeiros. $\mathrm{Na}$ imbricação dessas diferentes materialidades significantes, o sentido da veracidade de um fato novo se desaloja e o sentido utilitário da ciência se dispersa.

Outras capas, outras brechas. No movimento entre os enunciados e as imagens aqui apresentados, chamo também a atenção para o sentido de tragédia que não nos abandona no laranja da capa de maio de 2010. Um laranja que inunda nosso olhar e reitera a tragédia, nos mostrando que aquela água carrega muita terra e muito mais que apenas terra, apesar de o conhecimento científico anunciar uma medida "contra novas 
tragédias". Importa buscar a falha no ritual (Cf. PÊCHEUX, 1990b) da leitura.

\section{Figura 4 - Capa Maio}

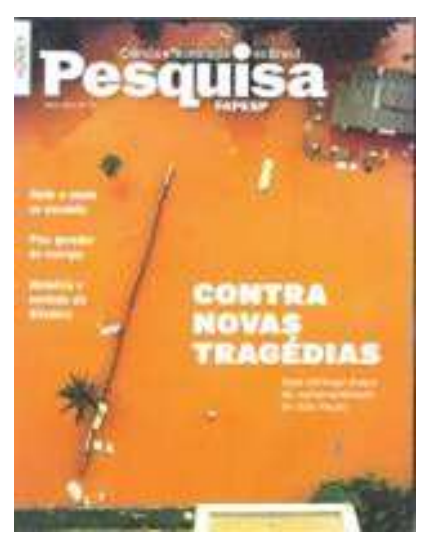

Fonte: Revista Ciência e Tecnologia no Brasil: Pesquisa FAPESP

A revista Pesquisa FAPESP, em sua injunção a divulgar conhecimento científico, nos apresenta a possibilidade de falar da equivocidade que constitui a relação entre ciência e informação, entre produzir conhecimento e divulgá-lo. E o sujeito leitor, constituído na injunção a saber do que se fala, a entender a produção científica divulgada na voz da informação, fica exposto a uma veracidade que coage, mas que falha na incompletude das relações significantes em funcionamento na contradição da história. Leitores que devem ser instruídos na veracidade de um mundo científico divulgado, mas cuja escuta fica demandada nas brechas simbólicas que a contradição e a incompletude abrem. Um rosto indígena que nos interroga no ressoar do 'mundo amazônico', a imagem da água laranja que carrega a 'tragédia'. 


\section{REFERÊNCIAS}

DUCROT, O.; TODOROV, T. Dicionário das Ciências da Linguagem. Lisboa: Publicações Dom Quixote, 1982.

GADET, F.; PÊCHEUX, M. A língua inatingível. Campinas: Pontes, 2004.

LAGAZZI, S. A materialidade significante em análise. In: TFOUNI, L.V., MONTE-SERRAT, D.M., CHIARETTI, P. (Orgs.). A Análise do Discurso e suas interfaces. São Carlos: Pedro \& João Editores, 2011, p. 311-324.

. Recorte significante na memória. In: INDURSKY, F.; Maria Cristina LEANDRO FERREIRA, M. C.; MITTMANN, S. (Orgs.). O discurso na contemporaneidade: materialidades e fronteiras. Vol. 1. São Carlos: Claraluz, 2009. p. 67-78.

LAGAZZI-RODRIGUES, S. Texto e autoria. In: ORLANDI, E.P.; LAGAZZI-RODRIGUES, S. (Orgs.). Introdução às ciências da linguagem: discurso e textualidade. Campinas: Pontes, 2006. p. 81-103.

NAVES, M. Marxismo e Direito. São Paulo: Boitempo, 2000.

ORLANDI, E. Divulgação científica e efeito-leitor: uma política social urbana. In: GUIMARÃES, E. (Org.). Produção e circulação do conhecimento: estado, mídia, sociedade. Campinas: Pontes, 2001a. p. 21-30.

Discurso e texto: formulação e circulação dos sentidos. Campinas: Pontes, 2001b.

PÊCHEUX, M. Semântica e discurso: uma crítica à afirmação do óbvio. Campinas: Editora da Unicamp, 1988.

O discurso: estrutura ou acontecimento. Campinas: Pontes, 1990a. . Delimitações, inversões, deslocamentos. Cadernos de Estudos Linguísticos, Campinas, n. 19, p. 7-24, Jul./Dez. 1990b.

SAUSSURE, F. de. Curso de lingüística geral. São Paulo: Cultrix, 1979.

Recebido em 30/10/11. Aprovado em 14/12/11. 
Title: Equivocation in the circulation of scientific knowledge Author: Suzy Lagazzi

Abstract: Within the relationship between the production of knowledge deemed scientific and the disclosure thereof, I intend to discuss equivocation, defined by Michel Pêcheux as the juxtaposition of senses from different subject positions. As analysis material I take the covers of Revista Pesquisa FAPESP, a public science magazine published by the São Paulo Research Foundation. Wittin the theoretical framework of the materialistic Discourse Analysis, which lies in the relationship between linguistics, historical materialism, and psychoanalysis, I explore the verbal and image composition while attempting to understand how information permeates science.

Keywords: Scientific disclosure. Discourse Analysis. Word/image analysis.

Titulo: La equivocidad en la circulación del conocimiento cientifico Autor: Suzy Lagazzi

Resumen: En la relación entre la producción del conocimiento considerado como científico y su divulgación, me propongo a discutir la equivocidad, comprendida por Michel Pêcheux como la sobreposición de sentidos a partir de diferentes posiciones del sujeto. Tomo como objeto para mi análisis tapas de la Revista Pesquisa FAPESP, una revista de divulgación cientifica publicada por la Fundación de Amparo a la Pesquisa del Estado de San Pablo. Teniendo como referencial teórico el Análisis del Discurso materialista, que trabaja en la relación entre la linguistica, el materialismo bistórico y el psicoanálisis, exploro la composición de lo verbal y de la imagen en la búsqueda por comprender el atravesamiento de la ciencia por la información. Palabras-clave: Divulgación científica. Análisis del discurso. Análisis palabral imagen. 